\title{
On the Ethics of Cultural Heritage Protection*
}

\author{
ZHANG Yun-yan, HE Yan-mei \\ Shanghai Jiaotong University, Shanghai, China
}

\begin{abstract}
This paper tries to address the problem of a lack of ethics about intangible cultural heritage protection in current China from the perspective of the history of ideas. Though this is a not a new angle and many papers have given a more or less comprehensive discussion about this, this paper will endeavor to give a more systematic account. Seen from the perspective of ethics, the protection of cultural heritage in China is mainly challenged by imbalance or deviation from four aspects: Firstly, from the aspect of political justice; secondly, from the aspect of a lack of civic awareness; thirdly, from the aspect of excessive nationalism; fourthly, from the aspect of silent intellectuals.
\end{abstract}

Keywords: cultural heritage protection, ethics, political justice, civic awareness, excessive nationalism, public intellectuals

\section{Introduction}

The modern concept of cultural heritage is closely related to two Conventions formulated by the United Nations Educational Scientific and Cultural Organization ("UNESCO"), namely Convention Concerning the Protection of the World Cultural and Natural Heritage (1972) and Convention for the Safeguarding of the Intangible Cultural Heritage (2003). The combination of the two covers both the field of tangible cultural heritage and the field of intangible heritage, among them tangible cultural relics with outstanding universal values historically, artistically, scientifically and anthropologically, and intangible ones in the form of practice, performance, knowledge and skills and related materialized tools, objects, artifacts and cultural sites. Those kinds of intangible cultural heritage are a guarantee for the promotion of cultural diversity. The Chinese government signed the Convention in 2004, and thus became a convention-sponsor of the movement.

Set off against such a background, there is no wonder that the application for cultural heritage ("inscription") continues to be a hot topic in China. The enthusiasm behind some the inscription, however, seems to be a far cry from the principles of the UNESCO's Convention in which the primary aim of inscription is to protect and rescue the heritage. So, rather than appealing for cultural diversity, what they really have their eyes on is the huge economic potential of the heritage, and they do so under the excuses of asking for protection of the assets. In a closer observation of the values of cultural heritage, we could easily identity three principal functions of it: economic function, social function and cultural function. The economic function can directly bring economic

\footnotetext{
* Acknowledgements: This paper is supported by China National Find of Social Sciences "the Research of Fundamental Problems of the Contemporary Aesthetic and Criticism Forms" (15ZDB023).

ZHANG Yun-yan, Ph.D, an editor of the Journal Research on Marxist Aesthetics, and an associate Professor of Aesthetic and Cultural theory in Shanghai Jiaotong University. Email: zhangyunyan@sjtu.edu.cn.

HE Yan-mei, Master of English, Graduated from Shanghai Jiao Tong Univerity. Email:heyanmei0001@163.com.
} 
benefits, which is understandable and reasonable under the Convention premise of "strict protection, rational use". In addition, the heritage could be better protected if all parties have a balanced interests.

However, judging from the current situation in inscription, there exit two significant losses, one in legislation, one in ethics. To have related laws and a well developed ethics is to guarantee and standardize the inscription in the constitution. China now only has one law in this regard-Cultural Relics Protection Law, so we are in urgent need of supplementation. After a general survey of domestic discourses on intangible cultural heritage, I find that there is number of intellectuals who deem that the following issues need our focused attention: (1) the study on how to draw on the experience of foreign countries in the protection of intangible cultural heritage; (2) the basic theoretical the study of intangible cultural heritage protection, including theories, methods and strategies in the study of heritage's values, characteristics and conservation; (3) study combining the protection of cultural heritage and the development of cities and provinces; (4) study on the relationship between cultural heritage and tourism; (5) study on the relationship between cultural heritage and folklore; (6) case study of the commercialization of the intangible cultural heritage resources. ${ }^{1}$

These studies are largely focused on the technical aspects of intangible cultural heritage protection, legislation, on practical protection methods, approaches, and on the analysis of economic function based on actual cases. Naturally those studies are essential in facilitating our protection of and harnessing the cultural heritage. The key problem, however, lies in that whether or not could we give a serious thought about the means of heritage conservation, and in the meantime, move on to ponder over the reasons for so doing, and the object to be protected, namely to press further into the spiritual aspects and historical traditions behind the concrete material; and only in such a way would we be able to do a better job in cultural heritage conservation while still sticking to our mission. The current challenge is for people to consider cultural heritage conservation as a self-evident theoretical premise. Yet I doubt that the importance of protecting the heritage is truly self-evident. Apparently, the tremendous economic potential of the cultural heritage entices people away from reflecting those questions, and the enormous economic and commercial interests behind inscription thus is pushing to limelight a series of implicit social problems. Many intellectual has given an adequate analysis of this phenomenon, and have adopted an international perspective to take into account a myriad of reasons, such as the absence or inadequacy of relevant laws. ${ }^{2}$ In this regard, the paper tries to address the problem of a lack of ethics from the perspective of the history of ideas. Though this is a not a new angle and many papers have given a more or less comprehensive discussion about this, this paper will endeavor to give a more systematic account.

\section{I}

What kind of issues does ethics focus on? Internally, it concerns people's virtue, and externally, justice and order of the political system. Another way to put it, externally, ethics embodies the love for justice, and internally, self-esteem. Compared with moral issues, which more focuses on the perspective of "subjectivity and individual", the angle of ethical issues is slightly different, and it is more on the side of objective and community. ${ }^{3}$ There must

\footnotetext{
${ }^{1}$ Bie Jinhua and Liang Baoer: A Summarize Of Intangible Cultural Heritage Protection Research In China [J]. Tourism BBS, 2008,Volume 1 (3),

${ }^{2}$ Lv Lihui: Under The International Vision Of Cultural Heritage Protection And Utilization [J]. Journal Of Learning and Exploration, 2008 (5),

${ }^{3}$ He Huaihong: What is ethics [M]. Beijing University Press, 2002, p. 9.
} 
exists external systematic conditions for someone to act out their inherent virtue in the real world. "Justice is an umbrella of all virtue", acclaimed Rolls, "and justice is the primary value of the social system". ${ }^{4}$ From the perspective of protecting cultural heritage, which is a very practical social activity, we are therefore more in need of the ethics of justice to take effects in the process. The ethics of justice, and the law, politics are supplementary to each other, with the ethics of justice functioning as the foundation of laws and politics, and which in turn protects the justice ethics. Therefore, in this sense, the protection of legislation and the intervention of ethics are two sides of the same coin. "The justice of law is not just one part but the whole of virtue, and the injustice is not one fraction but the entirety of evil". 5 Ethics and legal norms have a considerable overlap. For example, taking another's life is forbidden both by ethics and legal norms. "Law is the bottom line of morality". In a way we could say that the moral standard of the modern society is at its minimum level, which could be referred to as the bottom line of ethics, while the law might as well be called the bottom line of bottom line. ${ }^{6}$

Seen from the perspective of ethics, the protection of cultural heritage in China is mainly challenged by imbalance or deviation from four aspects:

Firstly, from the aspect of political justice: Some local governments spare no efforts financially to apply for cultural heritage. Their excessive desire for GDP effect and political performance lead to a greater pursuit of economic benefits than that of cultural or social benefits of the cultural heritage resources. The resulted insatiable appetite for power and money on the part of local governments, contrasted with a lack of corresponding financial mechanism, management mechanism and supervision mechanism in the protection of cultural heritage, which opens the door for government departments' excessive involvement in the decision making process of micro management, protection, management and exploitation of heritage, has entitled the departments a huge space for rent-seeking. To standardize and coordinate well between the central government and local government, between local government departments and regulatory agencies, business agencies, and between non-government organizations and the inheritors, is the ethical justice concerning the reasonable protection and development of cultural heritage, and also corresponds with the principles of government's macroeconomic management prescribed in the UNESCO's Convention. Only in this way could we avoid the possibility of putting the national interests in the hand of certain departments, which in turn are decided by certain personnels. So the corresponding ethics in this regard is mainly focused on how to deal with the relationship between officials and the general public, in which government departments are only agents rather than the owner of the cultural heritage, and the ownership of the cultural heritage belongs to local residents. According to the "first principle of justice" in Rawls' A Theory of Justice, in which he argued that each person is to have an equal right to the most extensive basic liberty compatible with a similar liberty for others, namely, everyone has equal rights, and the resource belongs to the people, so it is naturally to let them have the right to participate in the decision-making process. His "second principle of justice" goes further under the principle of equal opportunities to be in favor of the overprivileged, and tries to take care of the "least beneficiaries". However, currently not only the "second principle of justice" is hard to be implemented, the first principle of justice is often aborted for the the so-called collective interests coming first than personal interests.

\footnotetext{
${ }^{4}$ Li Yongyin: To Be Good: Moral Purpose And Mission Of Literature And Art [J]. Journal of Literary Criticism, 2009 (2).

${ }^{5}$ Li Yongyin: To Be Good: Moral Purpose And Mission Of Literature And Art [J]. Journal of Literary Criticism, 2009 (2).

${ }^{6}$ He Huaihong: What is ethics [M]. Beijing University Press, 2002, p. 49.
} 
Secondly, from the aspect of a lack of civic awareness: According to T Janoski's definition of citizenship, "each individual in a nation-state shares an equal footing with the universality of rights and obligations of both negative and positive membership", and "citizen with a free subjectivity is build on an independent personality and social contract", the realization of modernization is through the transformation of people from subjects to citizens, which was just as Marx once said, "people transformed from being dependent to independent". 7 The lack of civic awareness in the protection of cultural heritage in China is closely related with official's increased appetite, a case in point is the Earth Building inscription conflicts between the local residents and officials in Fujian Province. Those earth buildings are owned by some common people. After time and again of failed fights for their legitimate rights, during which organizers of the protest were pursued and detained by the local public security bureau, they gradually grew indifferent on the cause of the inscription and protection of earth buildings. Their great emotional shifts, from previous eagerness and hopes to make a fortune to later hatred and threatens to burn down their own houses, complaining that "had their houses were not some so-called world heritage, they could have an easier and freer life", explains how the public are reluctant to be a part of a competition with the officials for fear of damages to their vital interests. As a result, not only the local governments have made themselves come opposite to the equality and justice of ethics, and also damage the public's enthusiasm in the participation of public management of earth buildings. Furthermore, due to the public's indifference with participation, the conditions of the cultural heritage is getting worse, and the lack of civic awareness in turn further empowers the control by the government departments of the heritage, thus creating a vicious circle.

\section{III}

Thirdly, from the aspect of excessive nationalism: Yukio Nishimura, Vice-Chairman of the Society for the Protection of the International Monuments and Sites, and also a planning expert in Japan, once said that the world's cultural heritage is not a product of cultural nationalism, and on the contrary, it should transcend cultural nationalism, and be recognized as a part of cultural diversity. This is the bitter lesson drew from the two cruel world wars. The purpose of the World Heritage Convention is to evaluate the already diversified world with a variety of values, to do everything possible to protect the integrity of the world. Evaluation should be given to each side of the local diversity, and protect them as integral part of the world. ${ }^{8}$ Unfortunately, the excavation and development of cultural heritage is in the direction of honoring them as super national treasure, revering them as a symbol of cultural nationalism, which is a deviation from human's universal values. Just as what Yukio Nishimura once put it, "If standing before a piece of cultural heritage, we could be awed, and do not mind yet at the same time sympathize with those who created them, thinking we all belong to the world community, could this simple emotion then become the most precious one. Only when immersed in this kind of feeling, could we be moved beyond the cultural nationalism".

What is cultural nationalism? It is the manifestation of nationalism in the cultural domain. Then naturally it

\footnotetext{
${ }^{7}$ Gao Like: The Concept of Citizens of the May 4th Intellectuals, [A] From Publicity And Public Intellectuals [C]. Edited by Prof. Xu Jilin ,Jiangsu People's Publishing House, 2003, p. 222.

8 Yukio Nishimura: "World Heritage"-Beyond The Cultural Nationalism [J]. Interpreted by Zhang Song, From the Journal of Tongji University (Social Science Edition), 2003, Volume 14 (3).
} 
is necessary for us to take a look back at the history of nationalism. According to English scholar Elie Kedourie, nationalism is a doctrine coming into being in the Europe in the early 19th century. It claimed to provide a standard for an appropriate-sized population unit to organize an independence government, to exercise their legitimate power in the country, and also a standard for international community's rights organizations. To make a long story short, this doctrine believed that human are naturally divided into different nations, and attributed to some confirmable characteristics, different peoples could be recognized as belonging to a certain group, and the only legitimate form of the government is that of a national autonomous government. ${ }^{[8](p .1)}$ There are several distinct stages along the development of nationalism. People in the 18th century, during the age of Enlightenment, thought that the world was ruled by a unified and eternal natural law. People could discover and understand the rules with their reason that if governed by the natural law, people in society could embrace freedom and happiness. Though the law is universal, it does not mean that there is no difference between people, and it implies that there exists for everyone some kind of commonness that is more important than differences, which is the equal rights for freedom and happiness. According to this philosophical view, a nation is a community consisting of individuals that live together so as to better protect their own well-being, and the duty of the ruler is to make reasonable measures to maximize that well-being of residents who live within the territory. This is what a social contract does, uniting people and defining the rights and obligations of the ruler and citizens. "If citizens in a nation are truly affluent, then the ruler is successful, if not, then the ruler should feel sorry. Therefore, patriotism is not an utterly rational concept, it could be proven with concrete proof'. Consequently, the national cohesion and people's loyalty to it depends on the ability of the country to ensure its people's well-being. Goethe also agreed with this, as he argued in his On the love of the Fatherland, "Could we have such a fatherland? If we could have a place where we could rest and our properties could be safely kept, a land where we could grow food, a house where we could be warmly received, then of course we would believe we have a fatherland?" ${ }^{[8]}$ (pp. 2-4) Representative of the theory of traditional nationalism, such as Herder, Taine, Mr.Starr and Goethe, think that a nation is an eternal entity, and the integration of the other traditional elements and blood, race, language, religion, national life, state, national psychology and customs formed the identity, sense of belonging and loyalty of a nation. Yet Elie Kedourie thought otherwise, the French Revolution brought with it the possibility of overturning the current government and substituting it with a new one, and also brought about a change in the ideas of a ruler's rights. Revolution means that if the citizens of a country are no longer satisfied with the political situation of their society, they have the rights and powers to replace it with a more satisfactory one. "The entire sovereignty is originally in the hands of the national. Any group, any individual can't exercise the powers which the sovereignty have not clearly granted" (The Universal Declaration of Human Rights and Citizenship). Hobsbaum shared the same idea that the examination of the modern concept of nationalism should start from the era of revolution (1789-1848). The Universal Declaration of Human Rights of French Revolution declared that all ethnic groups enjoy the independent sovereignty, regardless of their national size, race, geographic location. The sovereignty of the people should not be deprived. ${ }^{[9](\mathrm{p} .149)}$ The concept of modern nation state and the awareness of national self-determination thus began. It can be said that the two theories of nationalism and liberalism can't 
be separated from the background of the French Revolution. Elie Kedourie believed that after the French Revolution, nationalism was considered as an ideology. You can see this point by comparing it with the constitutional politics. Constitutional politics is expected to focus on public affairs, free the community from foreign attacks, mediate and compromise the differences and conflicts among various groups through political institutions and a fair legislation and administration, and place the power of law above everything else including any important or powerful partial interests. While the ideology of politics is rather different. Such politics attaches importance to establishing a state where everyone can live happily ever after like in a fairy tale. In order to obtain this goal, ideologically... nation and society are regarded as a cleaned canvas, which is then easily repainted on with beautiful illusions of justice, virtue, and happiness... Such canvas-wiping behavior is certain to attract, in a speed quicker than you could ever imagine, autocracy, law-breaking and atrocity. The result is that real peace and happiness will be destroyed far beyond repair. This kind of ideology of politics will lead to a permanently intense state of disasters and self-destruction... There exists a division between the government and the subject. For the nationals, government is an external compelling force that makes arbitrary decisions for them. While on the side of government, nationals are just some abstract numbers they refer to when formulating policies. People living in such countries are also divided individually, lacking a sense of solidarity and mutual accordance. The same is true of their souls. Such national autonomous rights should take the main responsibility for bringing about chaos in the international community. ${ }^{9}$ People with this kind of understanding of nationalism are not in the minority, which also demonstrates a contrast between modern thoughts and traditional thoughts of nationalism. For example, Anthony Giddens once compared nation state to a powerful container for it keeps a tight tab on the social life of its people. Anthony Smith stated in his Nationalism, "ethnics, nation state, ethnic identity, and the entire nation state international community are modern phenomenon". Nationalism is an ideology, and it is nationalism that created a nation state rather than the revers. Benedict Anderson argued that ethics is an artificially constructed symbol, a modern "cultural artifact" based on imagination, therefore a "imagined communities" as he called it. ${ }^{10}$ Eli Kaidu was critical and vigilant towards nation states with such kind of political ideology. In particular, he believed that in authoritarian countries, nationalism and liberalism are far from being a twin as their sources are, and rather they are a pair of opposing principles. In these countries, people know nothing of a constitutional government, yet the idea of nationalism spread very fast. In such country, if the ruling class or a considerable number of people in the ruling class turned to believe in nationalism, it would be really easy for them to manage the country by this doctrine. In this case, the doctrine will enable an autocratic regime to become more complete and consolidate... Since the essence of nationalism is the merging of individual will into the national will, so rulers in authoritarian regime will seek obedience from its people not only behaviorally but also emotionally. Now with the help of modern technology and means of communications, obedience from the people is now more in demand than ever. ${ }^{11}$ This narrow nationalism overemphasizes national unity and national interests, therefore its implied association with violence and wars of aggression poses infinite hazard.

9 (British) Elie Kedourie: “A Preface of The Nationalism in the fourth edition”, Central Compilation Press, on January 1, 2002, pp. 6-8.

${ }_{10}$ Benedict Anderson: Imagined Communities: Reflections on the Origin and Spread of Nationalism, Shanghai People's Publishing House, 2003, p. 150.

${ }^{11}$ Elie Kedourie: The Nationalism ,Central Compilation Press, on January 1, 2002, pp. 104-105. 
From the beginning of the French Revolution to the year of 1848, nationalism has been shown throughout various ethnic groups' political movements, with its influence spreading over the whole of Europe. On the eve of 1848, Marx and Engels published the Communist Manifesto, which stated that "Due to the exploitation of the world market by bourgeois, production and consumption are no longer limited within one country's border and have become an international activity. No matter how sorry the reactionaries feel, still the middle class have dug up the ethnical base of industry". Local and national self-sufficiency and seclusion are now in the the past, and have been substituted by communication and interdependence in all aspects among all peoples...Locality has been fading every day. Lenin described more directly the phenomenon of capitalism developing all over the world, and enhanced status of nation states. He claimed that there were two trends among the burgeoning capitalism towards the problem of ethnic issues. The first was the awakening of nationals and the start of national movements, in which they fought against all national oppression for the establishment of a nation state. The second is a more frequent exchanges among various peoples, the resulted elimination of national barriers, and globalized capital, general economic life, politics, science and so on. Lenin also believed that the first trend dominated the development of capitalism in its early stages, and the second trend symboled the maturity of capitalism. ${ }^{12}$ We could see that even in those countries where nationalism is emphasized, community and the concept of globalization also come into being along with nationalism. As a matter of fact, Marx and Engels were also keenly aware of this reality in their time. Therefore, judging from the its beginning and development, nationalism was originally accompanied with people's pursuit of happiness and freedom. However, after the strengthening of national consciousness, the ideology of nationalism and liberal constitutional political become all the more counteractive with each other. Therefore, in order to better protect the world cultural heritage, there should be a dialectical attitude towards the understanding of the relationship between differences and commonness, diversity and universality, national characteristics and universal ethics. Among the current appealing for the protection of world cultural heritage, there exists, in addition to the demands of economic interest, the pursuit of the ideology of nationalism. Culture is the sum of lifestyles of a group of people, which of course is diversified. It is precisely because of the existence of differences, we could have the possibility of making multiple choices. But only with diversity but unity, the world would be torn apart and infested with endless conflicts. Xiao Xuehui, a scholar, argued that human values with human rights as its core and corresponding axioms provided baseline for the world's cultural diversity and richness. Cultural diversity contains a paradox that it includes those cultures with the tendency to eradicate diversity. So be alert to the risks of using the mechanism of diversity to eliminate cultural diversity. ${ }^{13}$ The Convention also pointed out that the purpose of protecting the world's cultural diversity lies in innovation, "Along with the changes of surrounding environments, their relationship with the nature, and historical conditions, communities and groups constantly innovate those time-honored intangible cultural heritage, and at the same time render themselves with a sense of identity and a respect for history, thus promoting cultural diversity and human creativity." The application criteria and conditions are as follows, "consider only those candidate intangible cultural heritage that comply

\footnotetext{
${ }^{12} \mathrm{Xu}$ Bo and Chen Lin: Globalization, Modernization and Nationalism: Reality and Paradox, From "the nationalism”, (British) Elie Kedourie, Central Compilation Press, on January 1, 2002, p. 1.

${ }_{13}$ Xiao Xuehui: The Cultural Diversity and the Universal Values, From "The Course of University Humanities", edited by Prof. Xia Zhongyi, Guangxi Normal University Press, 2003, pp. 233-237.
} 
with the needs of sustainable development, and is consistent with existing documents of international human rights, the needs of the mutual respect between groups and individuals."

\section{IV}

Fourthly, from the aspect of silent intellectuals. Here it involves the relationship between the the knowledge system of folk culture and the knowledge system of intelligentsia, which in current study is mainly reflected in the dilemma as to whether to maintain the heritage's original appearance or transform and develop it. The problem is rooted in the identification of the characteristics of the heritage, namely to identify the state of a certain piece of heritage as stable and original or dynamic. Should we keep the heritage's original state to maintain cultural diversity or should we transform and develop it in a civilized way so as to promote cultural diversity? The answer lies in role assignment and the technical division of labor between the general public and the intellectuals. This specific discussion could be explored in terms of arts, academics or techniques instead of ethics. However we should note that public intellectuals and professional intellectuals are two different concepts, yet such differences have not been paid with adequate attention in the current practice of cultural heritage protection, and it relies more on the penetration of professional knowledge by professional intellectuals, while at the same time gives little account and attention to the values and influence of public intellectuals. Such unbalanced emphasis is a lack of ethics in the aspect of cultural heritage conservation. In other words, the lack of ethics in the field of cultural heritage is mainly due to the absence of public intellectuals. The definition of public intellectuals have two sources. First, from aristocratic Russian intelligentsia of the nineteen century. Since their return from the West, they began to consciously draw on the ideas from western civilization in the process of domestic construction, and put forward many constructive opinions. They reflected the characteristics of the participation of intellectuals in the public affairs. Second, from the movement led by Zola in the vindication for Dreyfus, which borne witness to a joint letter by more than three thousands intellectuals in the protest of injustice made by the government. This movement, in which Zola was not fighting alone but with groups of intellectuals protesting the government's unjust exercise of power, marked the rise of critical intellectuals in large groups. Cultural protection is very much a practical activity, in process of which the intervention by intellectuals to criticize and supervise or to enlighten and guide is very necessary. In public domains as such, intellectuals could act as scholars and experts to constructively guide the mechanism of protecting and running of cultural heritage, and use their professional opinions and techniques in the development of original ecological resources, so as to conduct better exchanges with the world. They could also act as public intellectuals or spokesmen for conscience to engage in dialogues with the general public to let us understand that cultural heritage will not only be protected as national treasures, but also as a part of the diversified world, and we need an open mind to promote the national culture towards a direction conducive to the progress of human civilization, instead of staying conservative and regressing to the primitive form. When conscientious intellectuals stand up for the public to face the government, they begin to exert proper influence in the supervision and judgment of government's work, and make constructive opinions for government's policies. This is not a struggle with the government for ideological leadership, but a fulfillment of public concern based on human universal values by intellectuals. Public intellectuals can't shirk their responsibilities, in particular, to curb the trend of extreme nationalism in ideology; to enlighten people to have a dialectic memory of the negative legacy; to bring into play the education function of 
the black tourism in addition to its entertainment function; to protect and rescue the heritage, and at the same time resist the the temptation of commercial interests, beware of the sinking tendency of populism. Unfortunately, the domestic cultural heritage protection in this regard is still a vacuum, some professionals and experts, the number of who are originally quite small, just provide professional guidance while act as public intellectuals from time to time, and once their points of view are inconsistent with local economic benefits or GDP obtaining methods, local governments will decline their intervention on the ground that expertise is not suitable. This can only lead to the degradation of the original ecological state of cultural heritage to a monotonous form, and will not enable the heritage to evolve and develop into more diverse forms. What is worse, the cultural heritage might be faced with the tragic fate of being destructed or dismantled. Therefore, it is naturally that public intellectuals should, on behalf of ethics, play a leading role in our protection of world cultural heritage.

\section{References}

He Huaihong. (2002). What is ethics [M]. Beijing University Press.

Xu Jilin. (Ed.). (2003). Publicity And Public Intellectuals [C]. Jiangsu People's Publishing House.

Elie Kedourie. (January 1, 2002). The Nationalism. Central Compilation Press.

Benedict Anderson. (2003). Imagined Communities: Reflections on the Origin and Spread of Nationalism. Shanghai People's Publishing House.

Xia Zhongyi. (Ed.). (2003). The Course of University Humanities. Guangxi Normal University Press. 